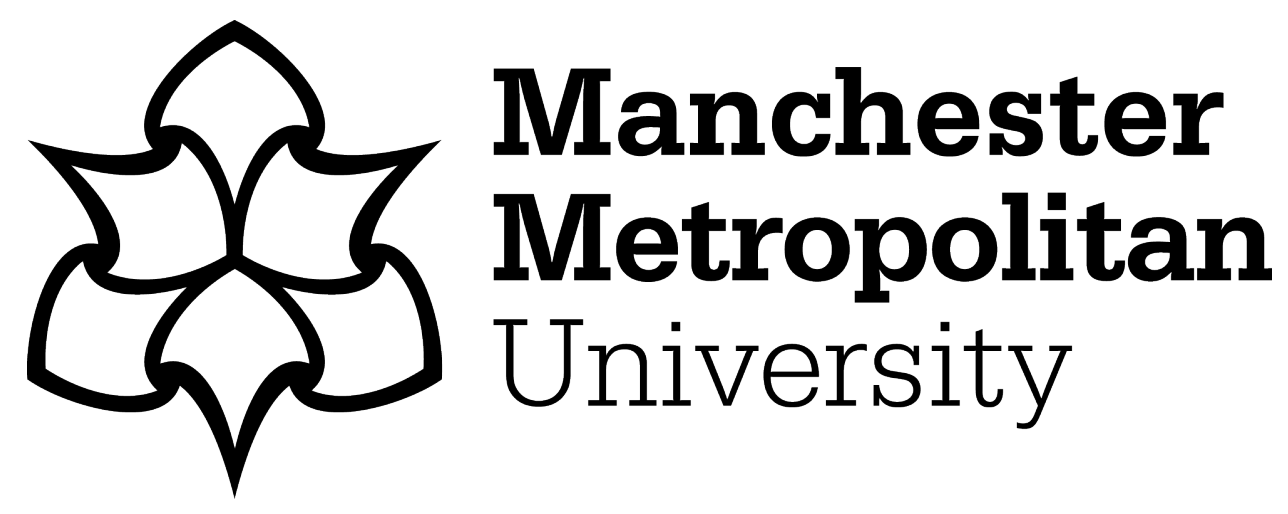

Scelles, Nicolas ORCID logoORCID: https://orcid.org/0000-0002-6177-5307 (2021) Impact of the Special Issues in Sport Management and Sociology Journals. Managing Sport and Leisure. ISSN 2375-0472

Downloaded from: https://e-space.mmu.ac.uk/628716/

Version: Published Version

Publisher: Taylor \& Francis

DOI: https://doi.org/10.1080/23750472.2021.2008267

Usage rights: Creative Commons: Attribution-Noncommercial-No Derivative Works 4.0

Please cite the published version 


\section{Managing Sport and Leisure}

\section{Impact of the special issues in sport management and sociology journals}

\section{Nicolas Scelles}

To cite this article: Nicolas Scelles (2021): Impact of the special issues in sport management and sociology journals, Managing Sport and Leisure, DOI: 10.1080/23750472.2021.2008267

To link to this article: https://doi.org/10.1080/23750472.2021.2008267
(c) 2021 The Author(s). Published by Informa UK Limited, trading as Taylor \& Francis Group

\section{曲 Published online: 29 Nov 2021.}

\section{E Submit your article to this journal $\pi$}

Џlll Article views: 430

Q View related articles $\square$

View Crossmark data $\asymp$ 


\title{
Impact of the special issues in sport management and sociology journals
}

\author{
Nicolas Scelles
}

Faculty of Business and Law, Department of Economics, Policy and International Business, Manchester Metropolitan University, Manchester, UK

\begin{abstract}
Rationale/purpose: There is a lack of evidence of the impact of the special issues (SIs) published in sport management and sociology journals compared to "normal" issues, as well as the differing impacts of different Sls. This review analyses the impact of the Sls published in these journals over the 2014-2020 period.

Design/methodology/approach: Two analyses were conducted based on Scopus data: "raw" and "relative" (SI cites divided by journal cites outside the SI). 205 SIs were identified, of which 180 had a CiteScore.

Findings: Sls are more impactful than "normal" issues, in particular when they have an appropriate focus (broad enough but not too diluted). Besides, the mix between reviews and esports appears particularly impactful, as exemplified by the reviews published by Sport Management Review in 2018.

Practical implications: A SI has a higher impact if it has an appropriate focus on a trendy topic and includes reviews.

Research contribution: The review evidences the impact of the Sls in sport management and sociology journals.
\end{abstract}

\section{ARTICLE HISTORY}

Received 20 October 2021

Accepted 16 November 2021

\section{KEYWORDS}

Impact; special issues; sport management; sport sociology; Scopus CiteScore

\section{Introduction}

Journal impact factors are indicators of the average impact made by the articles published by academic journals over a specific period. The fact that journals communicate on their impact factors, e.g. on the lending page of their website and on their social media platforms, is a sign of how important they are considered to assess their quality. This is despite the limitations of impact factors, such as the fact that they are not representative of the impact of the "average" article published in a journal. This is because the impact of a journal usually comes from a few highly cited articles, while most articles have a lower number of citations
(Kiermer, 2016). It remains that impact factors are used to benchmark journals against each other and, as such, are important metrics when it comes to choose which journal to target and / or to read.

Another important aspect of the "life" of an academic journal is the publication of special issues (SIs). SIs tackle a specific topic, with the aims of attracting a broad readership and being impactful. The impact of Sls was already observed in the field of management 15 years ago, with some evidence of a positive effect compared to regular issues (Conlon et al., 2006). More recently, Sainte-Marie et al. (2020) and Park and Kim (2021) also found a positive

CONTACT Nicolas Scelles N.Scelles@mmu.ac.uk Faculty of Business and Law, Department of Economics, Policy and International Business, Manchester Metropolitan University, Sport Policy Unit, Business School, All Saints Campus, M15 6BH, Manchester, UK (c) 2021 The Author(s). Published by Informa UK Limited, trading as Taylor \& Francis Group

This is an Open Access article distributed under the terms of the Creative Commons Attribution-NonCommercial-NoDerivatives License (http:// creativecommons.org/licenses/by-nc-nd/4.0/), which permits non-commercial re-use, distribution, and reproduction in any medium, provided the original work is properly cited, and is not altered, transformed, or built upon in any way. 
effect of SIs on scientific impact, respectively across disciplines and in tourism and hospitality journals. To our knowledge, in relation to sport management and sociology journals, there is no published evidence that SIs are more impactful than "normal" issues. However, Sls published recently in these journals have already received attention. Based on an analysis of the Sls in sport management and sociology journals over the 2014-2020 period, Scelles (2020) published an open access article on their key themes. 21 main themes were identified, leading to a so called "Agenda 21". In the conclusion of this article, it was noted that "Impact factors have not been investigated in this article but the analysis of the cites generated by the SIs identified here may be an extension of this research aiming to better understand the dynamics of the international scientific reviews in sport management" (Scelles, 2020, p. 39). As a follow up to Scelles (2020), the present review provides such analysis of the cites generated by the Sls in sport management and sociology journals over the 2014-2020 period. It aims to provide a better understanding of the impact of the Sls in these journals by evidencing such impact compared to "normal" issues and the differing impacts of the different Sls and key themes in sport management and sociology journals.

The paper is structured as follows. First, the methodology describes the data collection and analysis. Second, the results are presented, based on a "raw" analysis then the analysis of the impact of Sls relative to the impact of the journals. Both analyses cover the evolution over time, comparisons across Sls and key themes, and a focus on Managing Sport and Leisure. Last, the discussion and conclusion section provides the implications, limitations and future research directions.

\section{Methodology}

\section{Data collection}

In order to analyse the cites generated by the SIs in sport management and sociology journals over the 2014-2020 period, data were collected from Scopus, more inclusive than Web of Science and, as such, leading to more data available. Consistent with the CiteScore being calculated over a four-year period, the impact of the SIs was assessed over four periods, from the four-year period ending the year of their publication ( $t-3$ to $t$ ) to the four-year period ending three years later ( $t$ to $t+3$ ). The CiteScore (e.g. CiteScore 2020) is the number of cites over a four-year period for the articles published over this four-year period (e.g. the number of cites over 2017-2020 for the articles published over 2017-2020) divided by the number of articles published over this fouryear period (e.g. the number of articles over 2017-2020). This means that for the articles published in $t$ (e.g. in 2017):

- the cites in t (e.g. in 2017) are included in the calculations of the CiteScore in t (e.g. CiteScore 2017 covering 2014-2017), t+1 (e.g. CiteScore 2018 covering 2015-2018), t+2 (e.g. CiteScore 2019 covering 2016-2019) and $\mathrm{t}+3$ (e.g. CiteScore 2020 covering 2017-2020);

- the cites in $t+1$ (e.g. in 2018) are included in the calculations of the CiteScore in $t+1$ (e.g. CiteScore 2018 covering 2015-2018), t+2 (e.g. CiteScore 2019 covering 2016-2019) and $\mathrm{t}+3$ (e.g. CiteScore 2020 covering 2017-2020);

- the cites in $t+2$ (e.g. in 2019) are included in the calculations of the CiteScore in $t+2$ (e.g. CiteScore 2019 covering 2016-2019) and t +3 (e.g. CiteScore 2020 covering 2017-2020);

- and the cites in $t+3$ (e.g. in 2020) are included in the calculation of the CiteScore in $\mathrm{t}+3$ (e.g. CiteScore 2020 covering 20172020).

Besides, if there are any cites before $t$ (e.g. if the article was published online and cited prior to its release in a specific issue of the journal), they are also included in the calculations of the CiteScore: 
- the cites in t-3 (e.g. 2014) are included in the calculation of the CiteScore in t (e.g. CiteScore 2017 covering 2014-2017);

- the cites in t-2 (e.g. 2015) are included in the calculations of the CiteScore in t (e.g. CiteScore 2017 covering 2014-2017) and $t+1$ (e.g. CiteScore 2018 covering 2015-2018);

- and the cites in t-1 (e.g. 2016) are included in the calculations of the CiteScore in $\mathrm{t}$ (e.g. CiteScore 2017 covering 2014-2017), t+1 (e.g. CiteScore 2018 covering 2015-2018) and $\mathrm{t}+2$ (e.g. CiteScore 2019 covering 2016-2019).

The assessment was limited to three years for the Sls published in 2018, two years for the Sls published in 2019 and one year for the SIs published in 2020 since the 2021 (for the 2018, 2019 and 2020 SIs), 2022 (for the 2019 and 2020 SIs) and 2023 (for the 2020 SIs) impacts are not known yet. ${ }^{1}$ This is a limitation since the impact increases over time. The presentation of the results provided in the next section considers this limitation.

It must be noted that the CiteScore of the SIs is not readily available but needs to be calculated from the different articles counting towards impact published in the SI. This means that there is a need to check manually the publications of the $\mathrm{SI}$ from the journal website and identify them on Scopus. The identification process is illustrated here for the publications in the SIs published by Managing Sport and Leisure in 2020. On Scopus, the first step is to select "Sources" then enter and select the title of the journal. Once done, there is a need to click on the title of the journal then select "Scopus content coverage" then the "View citation overview" for 2020. From there, the publications of the SIs can be identified, with a need to distinguish between the two Sls published by the journal in 2020 .

There is also a need to check whether a publication should be counted or not. This is because not all articles count towards the CiteScore: articles considered as editorials or notes do not count. However, not all introductions (or conclusions when available) of Sls are considered as editorials or notes, meaning that it is necessary to check whether they are considered as articles (and as such count towards the calculation of the impact) or not. This information is important because it affects both the number of cites but also the number of publications to be used to calculate the number of cites per article.

\section{Data analysis}

The analysis provided in the next section initially focuses on the "raw" cites per article generated by the Sls, i.e. the total number of cites for a SI during each of the four periods analysed divided by the number of articles published in the SIs. In this initial analysis, the focuses are on:

- the average evolution of the impact of the Sls over time (from the four-year period ending the year of publication to the fouryear period ending three years later) from 2014 to 2020, depending on their year of publication;

- the comparison across SIs;

- the comparison across the 21 key themes identified in Scelles (2020);

- Managing Sport and Leisure.

The analyses of the average evolution of the impact of the Sls over time and the comparison across the 21 key themes identified in Scelles (2020) are based on the calculation of weighted average CiteScores. The weights rely on the number of articles published in the SI divided by the number of articles considered in the calculation of the CiteScore of the journal over the four-year period of interest. For example, the SI "Sport Community and Fan Movements in Neo- 
Liberal Times" published in Journal of Sport and Social Issues in 2015 had four articles. The CiteScore 2015 of the journal relied on 95 articles so the weight of the SI in the CiteScore 2015 of the journal was 4 / $95=4.2 \%$; the CiteScore 2016 of the journal relied on 100 articles so the weight of the SI in the CiteScore 2016 of the journal was $4 / 100=4 \%$; the CiteScore 2017 of the journal relied on 104 articles so the weight of the SI in the CiteScore 2017 of the journal was 4 / 104=3.8\%; the CiteScore 2018 of the journal relied on 103 articles so the weight of the $\mathrm{SI}$ in the CiteScore 2015 of the journal was $4 / 103=3.9 \%$.

There is a limitation with the "raw" analysis described in the previous paragraph in the sense that journals generating higher CiteScore are likely to publish SIs with higher CiteScore themselves. For this reason, it was decided to also conduct a "relative" analysis by looking at the ratio cites generated by the SI per article divided by cites generated by the journal per article outside the $\mathrm{SI}$ under consideration over the same period. ${ }^{2} \mathrm{~A}$ ratio equal to 1 means that the SI has the same impact as the journal. A ratio above 1 means that the $S I$ has a higher impact than the journal. For example, a ratio equal to 2 means that the SI has twice more impact than the journal. A ratio below 1 means that the SI has an impact lower than the journal. For example, a ratio equal to 0.5 means that the SI has half the impact of the journal, i.e. twice less impact. Similar to the "raw" analysis, the focuses are on the average evolution over time from 2014 to 2020, the comparisons across SIs and key themes, and Managing Sport and Leisure. The "relative" analysis enables to benchmark the impact of a SI compared to the journal where it was published over the same period, contributing to evidence whether Sls are more impactful than "normal" issues.

In total, 205 Sls published in 34 sport management and sociology journals were identified over the 2014-2020 period $^{3}$, of which 180 Sls published in 27 journals had a CiteScore. ${ }^{4}$ The analysis below is based on these 180 SIs, representing 1,534 publications counting towards

\footnotetext{
${ }^{2}$ An alternative approach would have been to divide by the cites generated by the journal per article outside all the Sls published over the period under consideration, i.e. the cites generated by the "normal" issues of the journal per article. However, data about all the Sls published in 2011, 2012 and 2013 would have been needed since they affect the CiteScores 2014 (2011-2014), 2015 (2012-2015) and 2016 (2013-2016). Their collection would have been extremely time consuming for a limited added value compared to the approach chosen here.

${ }^{3}$ There are actually 12 management and 10 sociology journals, but also 3 communication / media, 3 law, 2 marketing, 1 analytics, 1 development, 1 economics / finance and 1 policy journal. The rationale for the choice of the journals selected was to cover any sport journal relevant to sport management and sociology degrees and the units offered in such programmes. The full list of Sls is available as Appendix 2 in Scelles (2020). However, it must be noted that 11 additional Sls were identified since then:
}

- "Name, Image, and Likeness" edited by Madison Martin and Will Lindsey in Harvard Journal of Sports \& Entertainment Law in 2020;

- "Physical Education and Sport in Indonesia - Perspectives from 2020" edited by John Saunders in International Sports Studies in 2020;

- "Player Tracking Data in the National Football League (NFL)" edited by Michael Lopez in Journal of Quantitative Analysis in Sport in 2020;

- "Sport and Documentary" edited by Travis Vogan and CL Cole in Journal of Sport and Social Issues in 2020;

- "The Future of Sports Media in the Digital Age" edited by Jennifer L. Harker and Michael L. Mirer in Journal of Sports Media in 2020;

- "Organizing the World Cup: Organization, heritage and failing bids (1930-1998)" edited by Philippe Vonnard, Clément Astruc, Lorenzo Jalabert D'Amado and Nicola Sbetti, and "Soccer Under Authoritarian Regimes" edited by Jean-Michel De Waele and Alina Trif, both in Soccer \& Society in 2020;

- "Advances in Sport Management" edited by Anna Gerke and Birnir Egilsson in Sport, Business and Management in 2020;

- "Gender, Physical Education and Active Lifestyles: Contemporary Developments and New Challenges 2" edited by Annette Stride, Anne Flintoff, Hayley Fitzgerald, Scarlett Drury and Ruth Brazier in Sport, Education and Society in 2018;

- "Eric Dunning: A Tribute" edited by Dominic Malcolm and Ivan Waddington, and "SportsWorld V: The Evolving SportsWorld: Sports and Physical Activities in the Time of COVID-19" edited by John Nauright and Sarah Zipp, both in Sport in Society in 2020.

${ }^{4}$ Asia Pacific Journal of Sport and Social Science, Case Studies in Sport Management, Harvard Journal of Sports \& Entertainment Law, Journal of Applied Sport Management, Journal of Legal Aspects of Sport, Journal of Sports Media and Marquette Sports Law Review are not on Scopus. 
impact measured from the four-year period ending their year of publication to the fouryear period ending three years later (where possible). This means that, in theory, their number of cites was collected over a period of up to seven years, from three years before their publication in the $\mathrm{SI}$ (e.g. if they were published online three years before being released in the SI) to three years after their publication. In practice, none article was cited three years before its publication in the Sl, while some articles were cited two and / or one year before their release in the $\mathrm{SI}$.

\section{Results}

\section{"Raw" analysis}

\section{Evolution over time}

Table 1 provides the average evolution of the impact of the Sls depending on their year of publication, based on the "raw" analysis. Among the years for which all data are available, 2014 had the lowest average impact. One potential explanation is that impactful journals were underrepresented compared to less impactful journals, based on their impact over 2014-2017: in 2014, there were only two SIs from SSJ ${ }^{5}$, one from ESMQ, one from IJSPP, one from IRSS, one from JSSI, one from SES and one from SMR vs. seven from SiS, four from S\&S, two from IJSMM and two from SBM. The topics published in 2014 might be another explanation, with only one SI generating five cites per article per year on average vs. four in 2015, one in 2016 and seven in 2017 generating more than five cites per article per year on average, as evidenced below.

\section{Comparison across Sls}

The comparison across SIs reveals 14 SIs with an average of at least five cites per article per yearly CiteScore:
(1) "Sport Community and Fan Movements in Neo-Liberal Times" edited by Richard Giulianotti (JSSI 2015): 8.2

(2) "Blurring Sector Boundaries \& New Organizational Forms" edited by Katie and Laura Misener (JSM 2017): 7.7

(3) "Neoliberalism, Privatisation and the Future of Physical Education" edited by John Evans and Brian Davies (SES 2015a): 7.4

(4) "Managing Sport for Social Change / Sport-for-Development" edited by Emma Sherry, Nico Schulenkorf and Laurence Chalip (SMR 2015): 7.1

(5) "Corruption in Sport" edited by Lisa Kihl, James Skinner and Terry Engelberg (ESMQ 2017a): 7.1

(6) "Youth Sport Policy" edited by David Haycock (IJSPP 2016): 6.8

(7) "Sport Management Issues in an Era of Austerity" edited by Dan Parnell, Karl Spracklen and Peter Millward (ESMQ 2017b): 6.8

(8) "Learning Movement Cultures in Physical Education Practice" by Mikael Quennerstedt and Håkan Larsson (SES 2015b): 6.5

(9) "Young People and Sport" edited by Berit Skirstad, Milena Parent and Barrie Houlihan (SiS 2017a): 6.4

(10) "Entrepreneurship, Innovation and Sport Policy" edited by Vanessa Ratten and Joao Ferreira (IJSPP 2017): 6.3

(11) "Theory in Sports Tourism" edited by Sean Gammon, Gregory Ramshaw and Richard Wright (JST 2017): 5.5

(12) "Contemporary Qualitative Research Methods in Sport Management" edited by Larena Hoeber and Sally Shaw (SMR 2017): 5.2

(13) "Active Sport Tourism" edited by Heather J. Gibson, Matthew Lamont, Millicent Kennelly and Richard J. Buning (JST 2018): 5.1

(14) “Focus on New Media \& Sport 1" edited by David Leonard and CL Cole (JSSI 2014): 5.0.

${ }^{5}$ Acronyms for journals from now on, full names in Appendix. 
Table 1. Average evolution of the impact of the Sls depending on their year of publication - "raw" analysis.

\begin{tabular}{lcccccc}
\hline & Sls & $\mathrm{t}$ & $\mathrm{t}+1$ & $\mathrm{t}+2$ & $\mathrm{t}+3$ & Average \\
\hline 2014 & 23 & 0.3 & 1.1 & 2.5 & 4.4 & $\mathbf{2 . 0}$ \\
2015 & 22 & 0.5 & 1.9 & 3.9 & 6.4 & $\mathbf{3 . 1}$ \\
2016 & 17 & 0.4 & 1.5 & 3.3 & 5.5 & $\mathbf{2 . 6}$ \\
2017 & 29 & 0.4 & 1.5 & 3.3 & 5.6 & $\mathbf{2 . 4}$ \\
2018 & 31 & 0.3 & 1.5 & 3.8 & & $\mathbf{1 . 8}$ \\
2019 & 27 & 0.5 & 2.1 & & & $\mathbf{1 . 2}$ \\
2020 & 31 & 0.5 & & & & $\mathbf{0 . 5}$ \\
Average & $\mathbf{2 5 . 7}$ & $\mathbf{0 . 4}$ & $\mathbf{1 . 6}$ & $\mathbf{3 . 4}$ & $\mathbf{5 . 5}$ & $\mathbf{2 . 1}$ \\
\hline
\end{tabular}

Table 2 provides the evolution of the impact of the top 14 SIs over the four-year period. JST 2018 will increase its average once its impact in 2021 will be known and included. Interestingly, there are three other Sls published in 2018 and already close to four cites per article that will also increase their average once calculated over four years:

- "Sport Leadership: A New Generation of Thinking" edited by Lesley Ferkins, James Skinner and Steve Swanson (JSM 2018, seven articles): 4.0

- "Sponsorship Return on Investment" edited by Jonathan Jensen and Darin White (IJSMS 2018, six articles): 3.9

- "Sport, Physical Culture, and the Environment" edited by Kyle Bunds and Jonathan Casper (SSJ 2018, five articles): 3.8.

There are also two Sls published in 2019 and already above four cites per article or close to three cites per article that will also increase their average once calculated over four years:

- "Managing Sport for Health" edited by Michael Edwards and Katie Rowe (SMR 2019, 13 articles): 4.2

- "The Professionalization of Action Sports: The Changing Roles of Athletes, Industry and Media" edited by Holly Thorpe and Guillaume Dumont (SiS 2019, six articles): 2.9.

There are also four SIs published in 2020 and already above 2.5 cites per article that will also increase their average once calculated over four years:

- "Management, Marketing and Economy in Sports Organizations" edited by Manuel Alonso Dos Santos and Ferran Calabuig Moreno (SiS 2020, 10 articles): 3.5

- "New Routes within Brand Research in Sport Management: Facing Challenges between Heritage and Innovation" edited by Tim Ströbel and Claas Christian Germelmann (ESMQ 2020, six articles): 3.3

- "Managing Abuse and Integrity in Sport" edited by Emma Kavanagh, Adi Adams, Carly Stewart, Daniel Lock and Jamie Cleland (SMR 2020, 12 articles): 2.8

- "Innovation in Sport for Development and Peace" edited by Per Svensson and Adam Cohen (MSL 2020, five articles): 2.6.

Table 2. Evolution of the impact of the top $14 \mathrm{SIs}-$ "raw" analysis.

\begin{tabular}{lccccccc}
\hline & Articles & $\mathrm{t}$ & $\mathrm{t}+1$ & $\mathrm{t}+2$ & $\mathrm{t}+3$ & Average & Weighted average \\
\hline JSSI 2015 & 4 & 0.5 & 4.0 & 10.3 & 18.0 & $\mathbf{8 . 2}$ & $\mathbf{0 . 3 2}$ \\
JSM 2017 & 6 & 0.7 & 4.2 & 8.2 & 17.8 & $\mathbf{7 . 7}$ & $\mathbf{0 . 3 1}$ \\
SES 2015a & 7 & 1.4 & 4.4 & 9.0 & 14.7 & $\mathbf{7 . 4}$ & $\mathbf{0 . 2 0}$ \\
SMR 2015 & 11 & 1.5 & 4.6 & 8.9 & 13.5 & $\mathbf{7 . 1}$ & $\mathbf{0 . 4 5}$ \\
ESMQ 2017a & 3 & 2.0 & 4.7 & 8.3 & 13.3 & $\mathbf{7 . 1}$ & $\mathbf{0 . 1 6}$ \\
ISSPP 2016 & 8 & 2.1 & 5.3 & 8.8 & 11.3 & $\mathbf{6 . 8}$ & $\mathbf{0 . 3 4}$ \\
ESMQ 2017b & 2 & 0.5 & 5.0 & 9.5 & 12.0 & $\mathbf{6 . 8}$ & $\mathbf{0 . 1 0}$ \\
SES 2015b & 8 & 2.8 & 4.5 & 8.4 & 10.5 & $\mathbf{6 . 5}$ & $\mathbf{0 . 2 1}$ \\
SiS 2017a & 10 & 2.3 & 4.1 & 6.9 & 12.2 & $\mathbf{6 . 4}$ & $\mathbf{0 . 1 3}$ \\
ISSP 2017 & 5 & 0.2 & 2.2 & 7.2 & 15.4 & $\mathbf{6 . 3}$ & $\mathbf{0 . 1 8}$ \\
JST 2017 & 4 & 1.5 & 4.3 & 6.5 & 9.8 & $\mathbf{5 . 5}$ & $\mathbf{0 . 3 9}$ \\
SMR 2017 & 12 & 1.8 & 3.3 & 5.9 & 10.0 & $\mathbf{5 . 2}$ & $\mathbf{0 . 3 2}$ \\
JST 2018 & 5 & 1.4 & 4.6 & 9.4 & & $\mathbf{5 . 1}$ & $\mathbf{0 . 4 3}$ \\
JSSI 2014 & 4 & 1.0 & 2.3 & 5.5 & 11.3 & $\mathbf{5 . 0}$ & $\mathbf{0 . 2 0}$ \\
\hline
\end{tabular}


In addition to the average impact of the SIs, Table 2 also provides their weighted average, i.e. their average contribution per year to the impact of the journal when controlling for the weight of their number of articles in the total number of articles considered over the fouryear period of interest. In other words, the weighted average is the average of the (up to four) journal CiteScores coming from the SI. It can be seen that the three Sls contributing most in the top $14 \mathrm{SIs}$ are the ones published by SMR in 2015 and JST in 2017 and 2018, with the latter going to increase its weighted average once 2021 will be taken into account. JST has actually not only two but three of the five Sls contributing most when considering not only the top 14 Sls but all of them. This is due to the low number of articles published by the journal, which mechanically increases the relative importance of its SIs. The SI with the highest contribution overall is "Assessing the Trajectory and Challenges of the Sociology of Sport" edited by Elizabeth Pike, Steven Jackson and Lawrence Wenner (IRSS 2015, 50 articles), with an average contribution of 0.48 . Its very high number of articles explains it.

It is worth noting that none SI on esports is included in the analysis, as SIs on this topic are too recent. However, SMR published four reviews on esports in a single issue in 2018 (Volume 21, Issue 1). Their average impact over 2018-2021 will be at least 31.6 cites per article (as of 8 October 2021), i.e. almost four times more than the most impactful SI. Their weighted average was 0.64 as of 8 October 2021 , i.e. again above the highest average contribution in the analysis.

\section{Comparison across key themes}

Table 3 shows the evolution of the impact of the 21 key themes identified in Scelles (2020). It is worth noting that a $\mathrm{SI}$ can cover up to three themes, explaining why the sum of the SIs here (282) is more than the actual number of SIs (180). Some important elements here are that the number of Sls is different from one theme to one other and this number becomes lower over time if at least one of them was published since 2018 because the impact in 2021 is not available yet. For example, "Austerity" and "Overlooked Events" rely on a lower number of SIs than other SIs (respectively two and three) and only a single $\mathrm{SI}$ in $\mathrm{t}+3$. Although Table 3 indicates that they are the most impactful themes, some caution should be taken when interpreting this result. By contrast, the three other themes with an average impact above or close to three cites per article - namely "Development and Peace / Citizenship / Diplomacy / Nationalism / Racism", "Health and Wellbeing / Doping" and "Sport Policy and Politics: Others / Broader", all three belonging to the broader category "Sport Policy and Politics" in Scelles (2020) rely on more SIs.

Besides, in $\mathrm{t}+3$, "Performance / Multiple Objectives / Key Success Factors" does not rely on the SI "Sponsorship Return on Investment", while "Overlooked Sports" does not rely on the SI "Active Sport Tourism", both SIs being published in 2018. This is detrimental for both themes because these SIs are impactful and explains why the impact for these two themes is lower in $t+3$ than in $t+2$. This is despite the cites in $t+3$ being added to the cites in $t, t+1$ and $t+2$ for the calculation of the impact in $t+3$, which is supposed to lead to a higher impact in $\mathrm{t}+3$. This means that some caution should be taken before deriving any conclusion. Moreover, different journals have different impacts, meaning that aggregating data from different journals can be misleading. This is the reason why the next subsection focuses on the ratio cites generated by the SI divided by cites generated by the journal outside the SI.

\section{Managing Sport and Leisure}

The analysis specific to the journal is limited by the fact that only four Sls were published over the 2014-2020 period, all since 2018. This means that none SI published by the journal 
Table 3. Evolution of the impact of the 21 key themes - "raw" analysis.

\begin{tabular}{|c|c|c|c|c|c|c|}
\hline & Sls & $\mathrm{t}$ & $\mathrm{t}+1$ & $\mathrm{t}+2$ & $t+3$ & Average \\
\hline 1 - Globalization & 28 & 0.3 & 1.5 & 3.8 & 6.6 & 1.8 \\
\hline 2 - Impacts / Legacy of Mega Sports Events & 14 & 0.3 & 1.2 & 3.1 & 5.6 & 2.1 \\
\hline 3 - Austerity & 2 & 0.6 & 3.2 & 5.6 & 12.0 & 3.6 \\
\hline 4 - Development and Peace / Citizenship / Diplomacy / Nationalism / Racism & 11 & 0.9 & 2.0 & 4.3 & 6.4 & 3.2 \\
\hline 5 - Health and Wellbeing / Doping & 19 & 0.8 & 2.5 & 4.6 & 6.9 & 3.0 \\
\hline 6 - Sport Policy and Politics: Others / Broader & 12 & 0.7 & 2.3 & 4.7 & 9.6 & 3.0 \\
\hline 7 - Governance / Corruption / Integrity / Reputation & 11 & 0.6 & 1.4 & 2.3 & 3.7 & 1.5 \\
\hline 8 - Corporate Social Responsibility / Sustainability & 8 & 0.4 & 2.1 & 4.0 & 6.2 & 2.0 \\
\hline 9 - New Media & 9 & 0.3 & 1.0 & 2.7 & 4.6 & 1.3 \\
\hline 10 - Innovation / Knowledge Creation / New Organisations and Environment & 9 & 0.8 & 1.5 & 3.5 & 8.9 & 2.6 \\
\hline 11 - (Social) Entrepreneurship / Leadership / Value Co-Creation / Coopetition / Networks & 11 & 0.1 & 1.4 & 3.3 & 6.1 & 2.0 \\
\hline 12 - Performance / Multiple Objectives / Key Success Factors & 5 & 0.2 & 1.3 & 3.0 & 2.7 & 1.7 \\
\hline 13 - Youth & 6 & 0.8 & 2.1 & 4.0 & 5.8 & 2.8 \\
\hline 14 - Females / Gender & 11 & 0.3 & 1.4 & 3.2 & 3.8 & 1.9 \\
\hline 15 - Other Overlooked and / or Specific Publics & 25 & 0.5 & 1.7 & 3.7 & 6.5 & 2.6 \\
\hline 16 - Overlooked Sports & 9 & 0.7 & 2.1 & 4.1 & 1.8 & 2.1 \\
\hline 17 - Overlooked States & 12 & 0.4 & 2.3 & 5.4 & 9.3 & 2.4 \\
\hline 18 - Overlooked Events & 3 & 0.7 & 3.4 & 8.1 & 9.6 & 3.9 \\
\hline 19 - Research, Education, Practice and Impact & 40 & 0.4 & 1.6 & 3.4 & 6.1 & 2.0 \\
\hline 20 - Uniqueness of Sport (including History / Branding) & 32 & 0.2 & 0.8 & 1.6 & 2.6 & 1.0 \\
\hline 21 - External Recognition / Sport and Other Sectors & 5 & 0.2 & 1.1 & & & 0.4 \\
\hline
\end{tabular}

has an impact measured over a four-year period yet. The four Sls and their impact are:

- "Football, Business \& Management" edited by Michael Green and Tony Ghaye (2018, eight articles): average impact $=1.5$ (0.4 in 2018, 0.6 in 2019, 3.4 in 2020), weighted average impact $=0.10(0.03$ in 2018, 0.05 in 2019, 0.23 in 2020);

- "Creating and Managing a Sustainable Sporting Future" edited by Aaron Beacom and Vassilios Ziakas (2018, 10 articles): average impact $=1.0$ (0.0 in 2018, 0.3 in 2019, 2.9 in 2020), weighted average impact $=0.09(0.00$ in 2018, 0.03 in 2019, 0.24 in 2020);

- "Innovation in Sport for Development and Peace" edited by Per Svensson and Adam

Table 4. Average evolution of the impact of the SIs depending on their year of publication - "relative" analysis.

\begin{tabular}{lcccccc}
\hline & Sls & $\mathrm{t}$ & $\mathrm{t}+1$ & $\mathrm{t}+2$ & $\mathrm{t}+3$ & Average \\
\hline 2014 & 23 & 0.21 & 0.64 & 1.50 & 2.68 & $\mathbf{1 . 2 4}$ \\
2015 & 22 & 0.24 & 0.96 & 1.78 & 2.92 & $\mathbf{1 . 5 5}$ \\
2016 & 17 & 0.20 & 0.72 & 1.83 & 2.60 & $\mathbf{1 . 2 8}$ \\
2017 & 29 & 0.42 & 1.34 & 1.93 & 2.52 & $\mathbf{1 . 4 4}$ \\
2018 & 31 & 0.24 & 1.28 & 2.52 & & $\mathbf{1 . 0 9}$ \\
2019 & 27 & 0.32 & 1.09 & & & $\mathbf{0 . 6 4}$ \\
2020 & 31 & 0.23 & & & & $\mathbf{0 . 2 3}$ \\
Average & $\mathbf{2 5 . 7}$ & $\mathbf{0 . 2 7}$ & $\mathbf{1 . 0 6}$ & $\mathbf{1 . 9 5}$ & $\mathbf{2 . 6 6}$ & $\mathbf{1 . 1 8}$ \\
\hline
\end{tabular}

Cohen (2020, five articles): impact $=2.6$, weighted impact $=0.11$;

- "Football, Politics and Popular Culture" edited by Martin J. Power, James Carr, Stephen R. Millar, Dan Parnell and Paul Widdop (2020, nine articles): impact $=1.4$, weighted impact $=0.11$.

It is encouraging to observe the impact of these four SIs in 2020. This is despite the fact that 2020 does not represent $t+3$ for any of them - and even represents only $t$ for two of them - while $t+3$ is supposed to be the most impactful year for a SI over a four-year period. The "relative" analysis below confirms these encouraging signs.

\section{Impact of SIs relative to the impact of the journals}

\section{Evolution over time}

Table 4 provides the average evolution of the impact of the SIs depending on their year of publication in "relative" terms. The average ratio is above 1 , suggesting that Sls are more impactful than "normal" issues. The data here confirm to some extent the evolution based on the "raw" analysis (Table 1), with the 
highest impact for 2015 and the lowest impact for 2014 among the four years with all data available (2014-2017). However, 2014 is now much closer to 2016, which is now below 2017. In 2020, the relative impact of the 2018 SIs $(t+2)$ was slightly higher than the relative impact of the 2017 SIs $(t+3)$, the first time more recent SIs were more impactful in "relative" terms than less recent ones.

\section{Comparison across Sls}

The comparison across SIs reveals 14 SIs with an average ratio above 2.25 (i.e. an average impact more than twice and a quarter higher than the journal without the $\mathrm{SI}$ ):

(1) "Sport for Development and Peace: Theory Building and Programme Development" edited by Jon Welty Peachey (IJSMM 2015): 4.18

(2) "Young People and Sport" edited by Berit Skirstad, Milena Parent and Barrie Houlihan (SiS 2017a): 3.99

(3) "Football and Inclusivity" edited by Dan Parnell and David Richardson (S\&S 2014): 3.80

(4) "Sport Community and Fan Movements in Neo-Liberal Times" edited by Richard Giulianotti (JSSI 2015): 3.57

(5) "Contemporary Issues in Social Media in Sport" edited by Gashaw Abeza, Norm O'Reilly and Benoît Séguin (IJSC 2018): 3.21

(6) "Sport and Diplomacy" edited by Geoffrey Allen Pigman and Simon Rofe (SiS 2014): 3.11

(7) "Gender, Media, Sport" edited by Susanna Hedenborg and Gertrud Pfister (SiS 2015): 3.01

(8) "'Mapping the Terrain": Shaping the Landscape of Communication and Sport Scholarship" edited by Michael Butterworth (Ohio) and Jeffrey Kassing (C\&S 2015): 2.91

(9) "Rivalry in Sport" edited by Cody Havard (Memphis) and Vassilis Dalakas (SMQ 2017): 2.82
(10) "Sport, Unity \& Conflict" edited by Paddy Dolan and John Connolly (EJSS 2016): 2.73

(11) "Youth Sport Policy" edited by David Haycock (IJSPP 2016): 2.72

(12) "Theory in Sports Tourism" edited by Sean Gammon, Gregory Ramshaw and Richard Wright (JST 2017): 2.58.

(13) "Major Sporting Events: Beyond the Big Two" edited by John Harris, Fiona Skillen and Matthew McDowell (SiS 2017b): 2.39

(14) "Entrepreneurship, Innovation and Sport Policy" edited by Vanessa Ratten and Joao Ferreira (IJSPP 2017): 2.34.

Table 5 provides the evolution of the impact of the top 14 Sls in "relative" terms over the four-year period. Contrary to the "raw" analysis, not all SIs increased their impact over time. This is because the "relative" impact depends not only on the impact of the SI but also on the impact of the publications outside the SI.

IJSC 2018 may increase its average once its impact in 2021 will be known and included. Interestingly, there are five other Sls published in 2018 and already above 1.5 that may also increase their average once calculated over four years:

- "Sponsorship Return on Investment" edited by Jonathan Jensen and Darin White (IJSMS 2018, six articles): 2.25

- "Talent Identification and Talent Development in Junior-Elite Football in the UK" edited by Matthew Reeves and Simon Roberts (S\&S 2018, eight articles): 2.21

- "Active Sport Tourism" edited by Heather J. Gibson, Matthew Lamont, Millicent Kennelly and Richard J. Buning (JST 2018, five articles): 2.14

- "Fan Protest and Activism: Football from Below in South-Eastern Europe" edited by Andrew Hodges and Dario Brentin (S\&S 2018, eight articles): 1.88

- "Sport, Physical Culture, and the Environment" edited by Kyle Bunds and Jonathan Casper (SSJ 2018, five articles): 1.70. 
Table 5. Evolution of the impact of the top 14 Sls - "relative" analysis.

\begin{tabular}{lccccccr}
\hline & Articles & $\mathrm{t}$ & $\mathrm{t}+1$ & $\mathrm{t}+2$ & $\mathrm{t}+3$ & Average & Average contribution to journal CiteScore \\
\hline IJSMM 2015 & 4 & 0.00 & 1.84 & 5.52 & 9.38 & $\mathbf{4 . 1 8}$ & $\mathbf{1 9 \%}$ \\
SiS 2017a & 10 & 1.55 & 2.87 & 4.95 & 6.60 & $\mathbf{3 . 9 9}$ & $\mathbf{8 \%}$ \\
S\&S 2014 & 9 & 0.31 & 1.95 & 4.75 & 8.20 & $\mathbf{3 . 8 0}$ & $\mathbf{1 2 \%}$ \\
JSSI 2015 & 4 & 0.24 & 1.85 & 3.98 & 8.20 & $\mathbf{3 . 5 7}$ & $\mathbf{1 1 \%}$ \\
IJSC 2018 & 5 & 0.00 & 4.00 & 5.63 & & $\mathbf{3 . 2 1}$ & $\mathbf{7 \%}$ \\
SiS 2014 & 9 & 1.53 & 2.01 & 4.10 & 4.82 & $\mathbf{3 . 1 1}$ & $\mathbf{6 \%}$ \\
SiS 2015 & 8 & 0.51 & 2.86 & 3.67 & 5.02 & $\mathbf{3 . 0 1}$ & $\mathbf{1 4 \%}$ \\
C\&S 2015 & 5 & & & 2.80 & 3.01 & $\mathbf{2 . 9 1}$ & $\mathbf{2 5 \%}$ \\
SMQ 2017 & 5 & & 4.88 & 1.95 & 1.64 & $\mathbf{2 . 8 2}$ & $\mathbf{1 0 \%}$ \\
EJSS 2016 & 3 & & & 3.05 & 2.41 & $\mathbf{2 . 7 3}$ & $\mathbf{1 2 \%}$ \\
IJSPP 2016 & 8 & 0.84 & 2.15 & 3.39 & 4.50 & $\mathbf{2 . 7 2}$ & $\mathbf{1 6 \%}$ \\
JST 2017 & 4 & 1.08 & 3.00 & 2.36 & 3.86 & $\mathbf{2 . 5 8}$ & $\mathbf{4 \%}$ \\
SiS 2017b & 9 & 1.34 & 2.29 & 2.90 & 3.03 & $\mathbf{2 . 3 9}$ & $\mathbf{6 \%}$ \\
IJSPP 2017 & 5 & 0.07 & 0.75 & 2.56 & 5.99 & $\mathbf{2 . 3 4}$ &
\end{tabular}

Notes: CiteScores are not available in 2015 and 2016 for C\&S, and in 2016 and 2017 for EJSS. This gives the Sls published by these journals a competitive advantage since only their "best" years are included in the calculation of their average impact. Besides, the CiteScore was 0 for SMQ in 2017, i.e. none cite. Since it is not possible to divide by 0, there is no value displayed for SMQ 2017 in t. If replaced by 0, the average for SMQ 2017 becomes 2.12 (20th instead of 9th overall).

There are also four Sls published in 2019 and already above 1 that may also increase their average once calculated over four years:

- "The Professionalization of Action Sports: The Changing Roles of Athletes, Industry and Media" edited by Holly Thorpe and Guillaume Dumont (SiS 2019, six articles): 1.54

- "Communication and Soccer" edited by Lauren Burch, Matthew Zimmerman and Beth Fielding-Lloyd (IJSC 2019, six articles): 1.29

- "Sports Integrity: Ethics, Policy and Practice" edited by Andy Harvey (JGSM 2019, seven articles): 1.22

- "Sports Entrepreneurship and Innovation" edited by Vanessa Ratten and Kayhan Tajeddini (IJSMM 2019, seven articles): 1.18.

There are also three Sls published in 2020 and already above 1 that may also increase their average once calculated over four years:

- "Innovation in Sport for Development and Peace" edited by Per Svensson and Adam Cohen (MSL 2020, five articles): 2.09

- "Management, Marketing and Economy in Sports Organizations" edited by Manuel Alonso Dos Santos and Ferran Calabuig Moreno (SiS 2020, 10 articles): 1.73
- "Football, Politics and Popular Culture" edited by Martin J. Power, James Carr, Stephen R. Millar, Dan Parnell and Paul Widdop (MSL 2020, nine articles): 1.16.

In addition to the "relative" impact of the SIs, Table 5 also provides their average contribution to the CiteScore of the journal. The five best contributors are the SIs published by SMQ, IJSC, IJSMM, JST and C\&S. This can be attributed to the low number of articles published by these journals compared to others, which mechanically increases the contribution made by a single issue.

The average ratio for the four reviews on esports published by SMR in 2018 in its Volume 21, Issue 1, was 5.25 over 2018-2021 as of 8 October 2021, i.e. more than the highest ratio recorded above. In other words, even for SMR which has the highest impact among sport management and sociology journals, the combination of reviews and esports is a highly impactful mix. However, because SMR publishes much more articles than the five journals mentioned previously, the average contribution of the four reviews on esports to the journal was lower than the five Sls of these five journals ( $9 \%$ vs. $14 \%$ and more). 


\section{Comparison across key themes}

Table 6 shows the evolution of the impact of the 21 key themes identified in Scelles (2020) in "relative" terms. Some caution is required when interpreting the data due to the fairly low number of SIs for each key theme and the fact that some key themes have a lower percentage of SIs recorded in $\mathrm{t}+3$ (and even $\mathrm{t}+2$ ) than others. This tends to mechanically reduce their average impact. The key theme "Development and Peace / Citizenship / Diplomacy / Nationalism / Racism" is the only one with an average ratio above 2, although "Youth" is close to reach this target. The only other key theme above 1.5 is "Overlooked Events". Its ratio in t +3 solely depends on the SI "Impacts and Strategic Outcomes from Non-Mega Sport Events for Local Communities" edited by Marijke Taks, Laurence Chalip and Christine Green (ESMQ 2015, seven articles) so far. This is because the two other Sls on the topic, namely "Active Sport Tourism" (JST 2018) and "Consumer Behaviour and Trends in Sports Services" edited by Alexandris Kostas and Kaplanidou Kyriaki (IJSMM 2020, seven articles), were published since 2018. "New Media" is close to 1.5 , with potential for improvement since four of its nine Sls were published since 2018 (one in 2018, one in 2019 and two in 2020).

Six key themes have an average ratio below 1. "Overlooked Sports" suffers from two SIs published in 2018, four in 2019 and two in 2020 among its nine SIs (the other one was published in 2014), which mechanically reduces its average impact and explains why its impact in $\mathrm{t}+3$ is lower than in $\mathrm{t}+2$. "Governance / Corruption / Integrity / Reputation" also suffers from two Sls published in 2018, one in 2019 and three in 2020 among its 11 SIs, while the SI "Corruption in Sport" (ESMQ 2017, 3 articles) has a limited weighted impact (despite its high impact per article as evidenced in the "raw" analysis above) due to its low number of articles. "External Recognition / Sport and Other Sectors" suffers from not having any SI with impact in $\mathrm{t}+2$ and $\mathrm{t}+3$ yet, however even its impact in $t+1$ is the lowest among the 21 key themes.

Among the other key themes, the average impact of "Females / Gender" (1.16) is slightly below the average across all key themes (1.18). One may find that this key theme is not as impactful and trendy as the growing number of publications in this area may let think (Scelles \& Pfister, 2021; Valenti et al., 2018). However, a closer look at its 10 SIs shows a mix of very specific focuses for seven SIs - either geographical (Sub-Saharan Africa; United States; Global South) or topical (sex integration in sport and physical culture; gender in physical culture; extraordinary sportswomen; gender, physical education and active lifestyles) - or interactions with other dimensions for the other three SIs (media; international development and politics; representations and audience receptions of race/ethnicity, gender and nation).

Interactions with other dimensions seem to be positive, in particular for the first two mentioned (respectively 7th with a ratio of 3.01 and 29th with a ratio of 1.90), a little bit less so for the third one (58th with a ratio of 1.37, which remains above 1 so more impactful than the journal without the SI), which may be due to the higher number of dimensions involved that dilutes too much the focus. By contrast, the very specific focuses of the other seven Sls seem to have hindered their impact, compared to broader geographical and / or topical focuses (less so for the SIs on sex integration in sport and physical culture and SubSaharan Africa, the only ones among these seven Sls with a ratio above 1 , respectively 51 st with a ratio of 1.53 and 65 th with a ratio of 1.23; besides, some of these Sls were published since 2018, meaning they can still increase their average ratio). This suggests the need for a right balance, with a focus broad enough while not making too many dimensions interacting, which may dilute the focus. 
Table 6. Evolution of the impact of the 21 key themes - "relative" analysis.

\begin{tabular}{|c|c|c|c|c|c|c|}
\hline & Sls & $\mathrm{t}$ & $\mathrm{t}+1$ & $\mathrm{t}+2$ & $\mathrm{t}+3$ & Average \\
\hline 1 - Globalization & 28 & 0.22 & 0.90 & 2.23 & 3.12 & 1.04 \\
\hline 2 - Impacts / Legacy of Mega Sports Events & 14 & 0.20 & 0.92 & 2.22 & 2.89 & 1.30 \\
\hline 3 - Austerity & 2 & 0.19 & 1.06 & 1.99 & 3.03 & 1.17 \\
\hline 4 - Development and Peace / Citizenship / Diplomacy / Nationalism / Racism & 11 & 0.55 & 1.18 & 2.80 & 3.99 & 2.07 \\
\hline 5 - Health and Wellbeing / Doping & 18 & 0.28 & 0.95 & 1.89 & 2.97 & 1.21 \\
\hline 6 - Sport Policy and Politics: Others / Broader & 12 & 0.35 & 1.06 & 1.75 & 3.82 & 1.23 \\
\hline 7 - Governance / Corruption / Integrity / Reputation & 11 & 0.20 & 0.85 & 1.37 & 2.34 & 0.86 \\
\hline 8 - Corporate Social Responsibility / Sustainability & 8 & 0.20 & 1.03 & 2.86 & 5.04 & 1.30 \\
\hline 9 - New Media & 9 & 0.46 & 1.65 & 2.55 & 3.93 & 1.44 \\
\hline 10 - Innovation / Knowledge Creation / New Organisations and Environment & 9 & 0.41 & 0.94 & 1.32 & 2.93 & 1.07 \\
\hline 11 - (Social) Entrepreneurship / Leadership / Value Co-Creation / Coopetition / Networks & 11 & 0.07 & 1.93 & 1.57 & 2.45 & 1.23 \\
\hline 12 - Performance / Multiple Objectives / Key Success Factors & 5 & 0.20 & 0.80 & 1.64 & 2.52 & 1.12 \\
\hline 13 - Youth & 6 & 0.40 & 1.57 & 2.96 & 3.84 & 1.97 \\
\hline 14 - Females / Gender & 10 & 0.23 & 0.90 & 1.62 & 2.73 & 1.16 \\
\hline 15 - Other Overlooked and / or Specific Publics & 25 & 0.24 & 0.85 & 1.75 & 2.90 & 1.21 \\
\hline 16 - Overlooked Sports & 9 & 0.40 & 0.88 & 1.86 & 0.94 & 0.97 \\
\hline 17 - Overlooked States & 12 & 0.16 & 0.83 & 2.39 & 2.77 & 0.86 \\
\hline 18 - Overlooked Events & 3 & 0.40 & 1.22 & 3.24 & 3.11 & 1.53 \\
\hline 19 - Research, Education, Practice and Impact & 39 & 0.28 & 0.79 & 1.64 & 2.51 & 0.97 \\
\hline 20 - Uniqueness of Sport (including its History / Branding) & 32 & 0.15 & 1.01 & 1.17 & 1.92 & 0.90 \\
\hline 21 - External Recognition / Sport and Other Sectors & 5 & 0.11 & 0.52 & & & 0.23 \\
\hline
\end{tabular}

\section{Managing sport and leisure}

The four Sls published by the journal and their impact in "relative" terms are:

- "Football, Business \& Management" edited by Michael Green and Tony Ghaye (2018, eight articles): 1.18 (0.35 in 2018, 0.79 in $2019,3.00$ in 2020), 56th out of the 180 Sls with their average impact measured over the 2014-2020 period;

- "Creating and Managing a Sustainable Sporting Future" edited by Aaron Beacom and Vassilios Ziakas (2018, 10 articles): 1.00 (0.00 in 2018, 0.37 in 2019, 2.61 in 2020), 75th;

- "Innovation in Sport for Development and Peace" edited by Per Svensson and Adam Cohen (2020, five articles): 2.09, 22nd;

- "Football, Politics and Popular Culture" edited by Martin J. Power, James Carr, Stephen R. Millar, Dan Parnell and Paul Widdop (2020, nine articles): 1.16, 68th.

The two SIs published in 2018 have already a ranking in or almost in the top $40 \%$ of all the SIs analysed, with an improvement of their ranking expected once $t+3$ (2021) will be taken into account. The two Sls published in 2020 are already in the top $40 \%$ and even almost in the top $10 \%$ for one of them, despite only t (2020) being considered so far. This is promising for the journal and gives credit to the strategy followed over the recent years with targeting SIs, in relation to the heritage and future of the journal (Parnell \& Wilson, 2020).

\section{Discussion and conclusion}

\section{Implications}

When it comes to target impactful SIs for a journal, at least three implications can be derived from the analysis conducted here. A first implication that has been emphasized when dealing with the specific case of the key theme "Females / Gender" is the need for a right balance, with a topic focused enough but not too narrowly focused. There also seem to be some themes that are particularly impactful, which leads to the second implication about targeting trendy topics. The first two implications should ensure a fairly high number of submissions and eventually publications. This is an important condition so that the SI contributes to the impact of the journal in more than a marginal way. Esports appears as one of the trendy topics, if not the trendiest (maybe with 
Covid-19 for which it is too early to provide evidence). However, this may be due to a "first mover advantage" (i.e. early publications on the topic gain many cites) and is based on reviews that are overall more impactful than "original" articles. This leads to a third implication: the need to publish reviews. This gives credit to the decision made by Managing Sport and Leisure to release a call for systematic review SI proposals for 2022.

In summary, a SI should have a higher impact if it has an appropriate focus (broad enough but not too diluted) on a trendy topic and includes reviews. This may not be the most surprising conclusion and may simply confirm intuition, but it is evidence based, which is always better when it comes to make decision.

\section{Limitations and future research}

It must be acknowledged that the present analysis has some limitations, opening the door to future updates and research. Some of them have already been mentioned earlier, such as a number of Sls without their impact in $t+3, t+2$ or even $t+1$ yet. Besides, as suggested in the introduction, the average per article for each $\mathrm{SI}$ does not inform about whether the impact comes from one single highly cited article or from the different articles published in the SI cited in a more homogeneous way. Moreover, the percentage of reviews (if any) published in each SI was not controlled for, despite the fact that reviews are usually more impactful than "original" articles. Another limitation is the focus solely on sport management and sociology journals, while SIs in sport management and sociology are also published in journals that are not specific to sport, as illustrated by the series "Sport Policy and Finance" in Sustainability (Peng \& Scelles, in preparation; Scelles \& Peng, 2021). An additional limitation is the assumption that impact should be measured over a four-year period, while some research may need more time to be impactful. Also, this is not because a key theme would have been identified as not particularly impactful in the present analysis that it has no potential for impact. Indeed, the impact identified here depends on a number of factors such as the specific topics that may have been very narrow or on the contrary not sufficiently focused, where the SIs were published and also when the SIs were published. Besides, the analysis assumes that each cite has the same value. Yet, Scopus produces indicators controlling for the prestige of the journals (Scimago) or the size of the reference list of the articles where publications are cited (Source-Normalized Impact per Paper). It must also be recognized that part of the popularity/appeal of involvement in Sls is the timescale of publication. Papers submitted outside Sls may well sit in an inbox for an extended period, but a $\mathrm{SI}$ is more focused in terms of timescale.

Beyond the limitations related to the methodology, there are also some limitations with the ideas of impact and impact factors themselves. Some SIs may not be impactful as measured by impact factors due to their specific focus, yet they may still have covered important topics. A lower impact applies to SIs focusing on specific sportspeople, historical aspects or fairly narrow geographical settings and / or topics. Yet, concluding that they should not have been published would be detrimental to the range and depth of the research published in sport management and sociology journals. This raises the question of the mission and meaning of the research published in these journals, which is the focus of a current call for papers by European Sport Management Quarterly (Gammelsaeter \& Anagnostopoulos, in preparation). Is making an impact as measured by impact factors the ultimate mission for a journal? If so, should it only publish SIs on trendy topics including reviews? If all journals apply this, what about the future of researchers working on not trendy yet meaningful topics? These questions are important for 
the future of sport management and sociology and their communities in a context where impact tends to shape research.

\section{Acknowledgements}

The author thanks an anonymous reviewer and the editor in charge of the paper for their useful feedback, as well as Manchester Metropolitan University for its support with this research. All errors are his own.

\section{Disclosure statement}

The author acknowledges that he is Associate Editor of the journal.

\section{References}

Conlon, D. E., Morgeson, F. P., McNamara, G., Wiseman, R. M., \& Skilton, P. F. (2006). From the editors: Examining the impact and role of special issue and regular journal articles in the field of management. The Academy of Management Journal, 49(5), 857-872. https://doi.org/10.5465/ amj.2006.22798160

Gammelsaeter, H., \& Anagnostopoulos, C. (Eds.). (in preparation). Special issue: Sport management: Mission and meaning for a new area. European Sport Management Quarterly. https://think. taylorandfrancis.com/special_issues/sport-manag ement-mission-meaning-new-era/

Kiermer, V. (2016, July 5). Measuring up: Impact factors do not reflect article citation rates. https:// theplosblog.plos.org/2016/07/impact-factors-donot-reflect-citation-rates/

Park, E., \& Kim, W. (2021). What are the drivers of citations?: Application in tourism and hospitality journals. Applied Sciences, 11(19), 9288. https://doi.org/ 10.3390/app11199288

Parnell, D., \& Wilson, R. (2020). Reflecting on our heritage and planning our future: 25 years of managing sport and leisure. Managing Sport and Leisure, 25(4), 241-245. https://doi.org/10.1080/ 23750472.2020.1730571

Peng, Q., \& Scelles, N. (Eds.). (in preparation). Special issue: Sport policy and finance II. Sustainability. https://www.mdpi.com/journal/sustainability/spe cial_issues/Sport_Policy_and_Finance_sustainability

Sainte-Marie, M., Mongeon, P., \& Larivière, V. (2020). On the topicality and research impact of special issues. Quantitative Science Studies, 1(1), 303-319. https://doi.org/10.1162/qss_a_00009

Scelles, N. (2020). Dynamics of publication in international scientific reviews in sport management: Towards an Agenda 21. Management et Organisations du Sport, 1, 1-71. https://doi.org/ 10.46298/mos2020-6190

Scelles, N., \& Peng, Q. (Eds.). (2021). Special issue: Sport policy and finance. Sustainability. https:// www.mdpi.com/journal/sustainability/special_iss ues/Sport_Policy_Finance

Scelles, N., \& Pfister, G. (2021). Policy and politics of women's sport and women in sport. International Journal of Sport Policy and Politics, 13(2), 201-206. https://doi.org/10.1080/19406940.2021.1936881

Valenti, M., Scelles, N., \& Morrow, S. (2018). Women's football studies: An integrative review. Sport, Business and Management: An International Journal, 8(5), 511-528. https://doi.org/10.1108/SBM-09-2017-0048 


\section{Appendix: Journals analysed}

\begin{tabular}{|c|c|c|}
\hline Acronym & Full name & Discipline \\
\hline APJSSS & Asia Pacific Journal of Sport and Social Science (not existing anymore) & Sociology \\
\hline CSSM & Case Studies in Sport Management & Management \\
\hline C\&S & Communication and Sport & Communication / Media \\
\hline EJSS & European Journal for Sport and Society & Sociology \\
\hline ESMQ & European Sport Management Quarterly & Management \\
\hline HJSEL & Harvard Journal of Sports \& Entertainment Law & Law \\
\hline IJSC & International Journal of Sport Communication & Communication / Media \\
\hline IJSMM & International Journal of Sport Management and Marketing & Management \\
\hline IJSPP & International Journal of Sport Policy and Politics & Policy \\
\hline IJSMS & International Journal of Sports Marketing and Sponsorship & Marketing \\
\hline IRSS & International Review for the Sociology of Sport & Sociology \\
\hline ISS & International Sports Studies & Sociology \\
\hline JASM & Journal of Applied Sport Management & Management \\
\hline JGSM & Journal of Global Sport Management & Management \\
\hline JHLSTE & Journal of Hospitality, Leisure, Sport and Tourism Education & Management \\
\hline JLAS & Journal of Legal Aspects of Sport & Law \\
\hline JQAS & Journal of Quantitative Analysis in Sport & Analytics \\
\hline JSSI & Journal of Sport and Social Issues & Sociology \\
\hline JST & Journal of Sport and Tourism & Management \\
\hline JSFD & Journal of Sport For Development & Development \\
\hline JSM & Journal of Sport Management & Management \\
\hline JSE & Journal of Sports Economics & Economics / Finance \\
\hline JSsM & Journal of Sports Media & Communication / Media \\
\hline MSL & Managing Sport and Leisure & Management \\
\hline MSLR & Marquette Sports Law Review & Law \\
\hline PCS & Physical Culture and Sport: Studies and Research & Sociology \\
\hline S\&S & Soccer \& Society & Sociology \\
\hline SSJ & Sociology of Sport Journal & Sociology \\
\hline SBM & Sport, Business and Management & Management \\
\hline SES & Sport, Education and Society & Sociology \\
\hline SiS & Sport in Society & Sociology \\
\hline SMEJ & Sport Management Education Journal & Management \\
\hline SMR & Sport Management Review & Management \\
\hline SMQ & Sport Marketing Quarterly & Marketing \\
\hline
\end{tabular}

